\title{
Universal Multiplex PCR: a novel method of simultaneous amplification of multiple DNA fragments
}

\author{
Daxing Wen and Chunqing Zhang*
}

\begin{abstract}
Background: Multiplex PCR has been successfully applied in many areas since it was first reported in 1988; however, it suffers from poor universality.

Results: A novel method called Universal Multiplex PCR (UM-PCR) was created, which simultaneously amplifies multiple target fragments from genomic DNA. The method has two steps. First, the universal adapter-F and universal adapter-R are connected to the forward primers and the reverse primers, respectively. Hairpin structures and cross dimers of five pairs of adapter-primers are detected. Second, UM-PCR amplification is implemented using a novel PCR procedure termed "Two Rounds Mode" (three and 28-32 cycles). The first round (the first three cycles) is named the "One by One Annealing Round". The second round (28-32 cycles) combines annealing with extension. In the first two cycles of the first round, primers only amplify the specific templates; there are no templates for the universal adapters. The templates of universal adapters begin to be synthesized from the second cycle of the first round, and universal adapters and primers commence full amplification from the third cycle of the first round.
\end{abstract}

Conclusions: UM-PCR greatly improves the universality of multiplex PCR. UM-PCR could rapidly detect the genetic purity of maize seeds. In addition, it could be applied in other areas, such as analysis of polymorphisms, quantitative assays and identifications of species.

Keywords: Multiplex PCR, Polymorphisms, Species, Genetic purity, Maize

\section{Background}

Maize, as one of the three major grain crops worldwide, is important for feed and industrial raw materials. It occupies an important position in world agricultural production. The genetic purity of maize seeds has received much attention. Low seed purity reduces the biomass, thereby affecting the final yield.

There are many methods for testing the genetic purity of seeds, such as morphological identification, identification by physical and chemical methods, identification by physiological and biochemical methods, and identification by molecular biology and cell biology [1-15]. Currently, protein and isozyme electrophoresis are widely used in seed genetic purity testing. Traditional detection

\footnotetext{
* Correspondence: cazhang@sdau.edu.cn

State Key Laboratory of Crop Biology, Agronomy College, Shandong Agricultural University, Tai'an, Shandong Province 271018, P. R. China
}

techniques still have an important role; however, most of them are time and labor intensive, and are vulnerable to environmental conditions. Thus, they struggle to meet the requirements of rapid and accurate testing of seed genetic purity. Modern molecular biology and information technology have been applied to the testing of seed genetic purity, with the aim of establishing a rapid and accurate indoor test method. Current research has focused on machine vision (i.e. imaging-based automatic inspection) $[1,16-23]$ and simple sequence repeat (SSR) detection $[4,5,8,11,14,24]$.

Over the last decades, the use of molecular techniques to detect seed genetic purity has been increasingly advocated. Typically, polymerase chain reaction (PCR) is applied to amplify short fragments of DNA from samples, and the PCR products are then identified by gel electrophoresis. The main PCR-based methods for testing seed genetic purity are random amplified polymorphic DNA 
(RAPD), restriction fragment length polymorphism (RFLP), amplified fragment length polymorphism (AFLP) and detection of SSRs $[2,4,5,14]$. However, these methods may have one or more disadvantages, including inferior reproducibility, low efficiency or high cost.

Multiplex PCR [25-46] has been successfully applied in many areas (e.g., analyses of mutations and polymorphisms, quantitative assays and identifications of species) since it was first reported in 1988 [47]. It can simultaneously amplify primer mixtures, thereby decreasing the detection cost and overcoming the weakness of single PCR detection, which only amplifies a pair of primers once [26]. Multiplex PCR requires three to five pairs of SSR primers for testing maize seed genetic purity. Multiplex PCR can complete the test in a single reaction. However, multiplex PCR has several disadvantages, such as complexity, low amplification efficiency, variable efficiency on different templates and poor universality, which restrict its commercial application [44].

The aim of this study was to develop a rapid and accurate molecular identification method for testing the genetic purity of maize seeds. We present a method, termed Universal Multiplex PCR (UM-PCR), which can simultaneously detect five SSRs. UM-PCR greatly improves the universality of multiplex PCR.

\section{Results}

\section{Validation of the utility of the adapters}

After a series of optimization assays, UM-PCR amplification was implemented using "Two Rounds Mode". The specific process is described in the methods and shown in Figure 1. Specific fragments representing SSRs were amplified using traditional SSR PCR primers and UM-PCR primers (identified with a $U$ in the following list: phi085, U-phi085, phi041, U-phi041, phi123, Uphi123, umc1478, U-umc1478, umc1268 and U-umc1268) from maize varieties Zhengdan 958 and Xianyu 335 (Figure 2A). The results suggested that Zhengdan 958 and Xianyu 335 could be identified based on the length of PCR products, with no cross-reaction. The bands amplified by "Two Rounds Mode" with U-primers were slightly larger (36 bp) than the bands amplified by routine PCR with SSR primers. The results showed that the amplification efficiency of U-primers was similar to that of SSR primers.

The same SSR fragments were also amplified using common primers as well as universal primers (identified with a C in the following list: U-phi085, C-phi085, U-phi041, C-phi041, U-phi123, C-phi123, U-umc1478, C-umc1478, U-umc1268 and C-umc1268) from Zhengdan 958 and Xianyu 335 (Figure 2B). The bands amplified by "Two Rounds Mode" with C-primers were indistinct and weaker than the bands amplified by "Two Rounds Mode" with U-primers. There were some severe non-specific amplification products in lanes 13-16 amplified by C-phi041, and the target fragments of 13-16 were very weak as a result. There were some slight non-specific amplification products in lanes 9-12 amplified by U-phi041. The results showed that the common adapter gave poorer results than the universal adapters.

\section{Validation of the utility of UM-PCR}

Validation of universal quintuple PCR conditions was performed with five pairs of U-primers and compared to the results individual pairs of U-primers. The optimized PCR amplification conditions were the same as those used above. In Figure 3A, amplifications from individual pairs of U-primers are shown in lanes 1-20, while lanes 21-24 show the corresponding quintuple PCR. In lanes $1-2$, the bands amplified by U-phi085 were less bright than those amplified in lanes 3-20. The optimized PCR amplification was that the amount of U-phi085 primers should be twice other U-primers. In lanes 21-22, the bands amplified by U-phi085 (the amount of U-phi085 was twice the other U-primers) were almost as bright as those amplified by the other U-primers, but were not as bright as those shown in lanes 1-2. Although the bands of lanes 21-24 were amplified by five pairs of U-primers, they showed more than five bands (SSR is codominant.). The results suggested that UM-PCR could generate clear band patterns using five pairs of U-primers. Accordingly, Zhengdan 958 and Xianyu 335 could be identified based on the length of PCR fragments, with no cross-reaction, by UM-PCR.

The quintuple PCR products that were amplified using five pairs of normal SSR primers (Figure 3B, lanes 1-4) showed bands corresponding to only two SSRs (phi041 and umc1478). The reason may be because the Tms of the two pairs of normal SSR primers is higher than the others, and the annealing temperature of the second round is very high in "Two Rounds Mode". The quintuple PCR products that were amplified using U-primers were present as clear bands (Figure 3B, lanes 5-8). The quintuple PCR products that were amplified using C-primers (Figure $3 \mathrm{C}$ ) were not as clear as those amplified using U-primers (Figure 3A, lanes 21-24). The results showed that the $\mathrm{C}$-primers were not optimal for UM-PCR. Similar results are shown in Figure 3D, E, with any differences being caused by the particular U-primer used. Importantly, UM-PCR could be applied for testing the genetic purity of maize seeds.

The genetic purity of a maize seed lot sampled from Zhengdan 958, which is the largest maize cultivar planted in China, was detected by UM-PCR using 200 seeds (Figure 4). Additional file 1 shows this in more detail. Figure 4 shows that 192 seeds were identified as Zhengdan 958, four seeds were identified as the female parent of Zhengdan 958, and four seeds were identified 


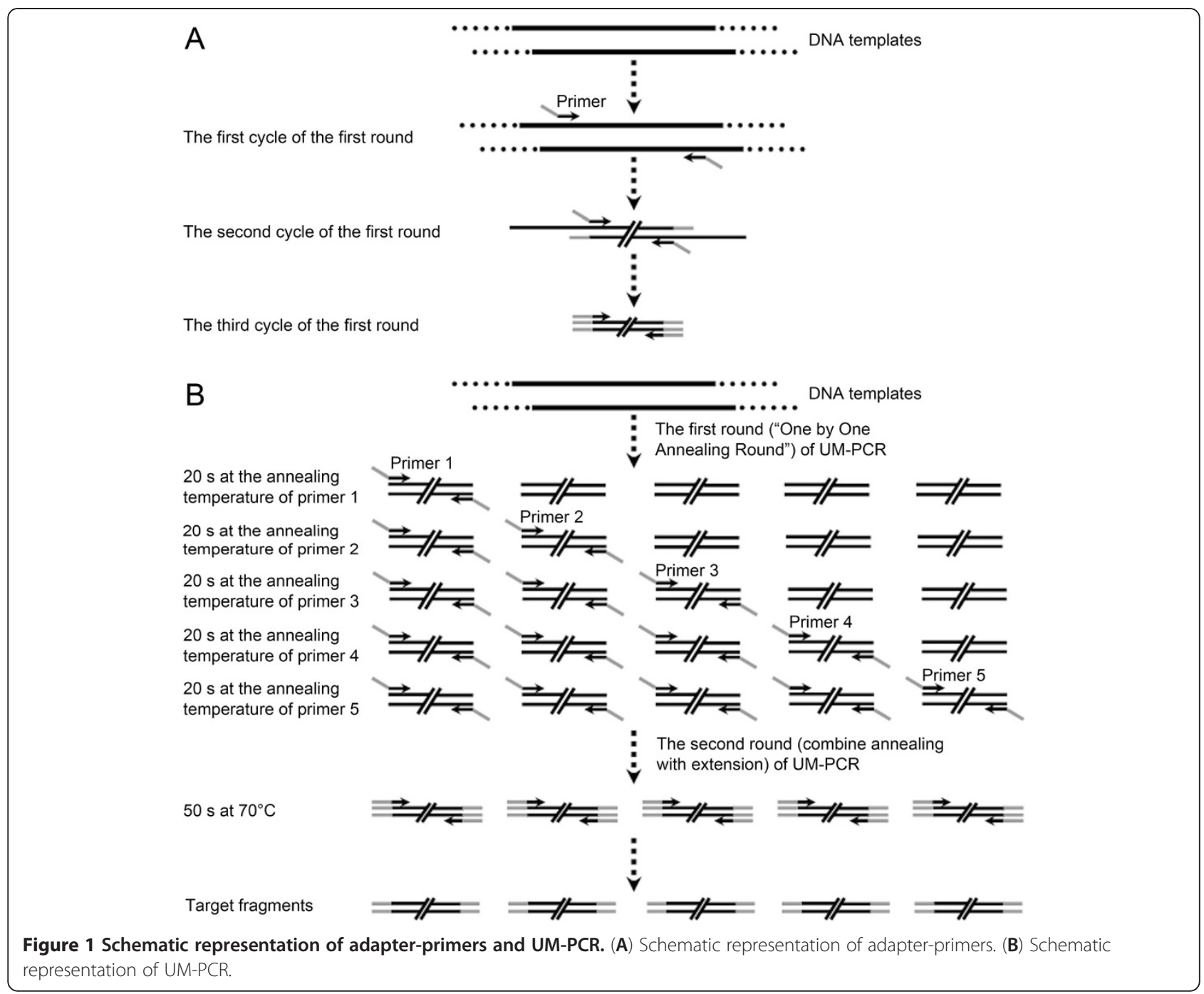

as off-type seeds. In these off-type seeds, U-phi085 showed different band patterns in lanes 7, 9 and 10 . U-phi041 showed a different band pattern in lane 8 . U-phi123 showed a different band pattern in lane 10 . U-umc1478 showed a different band pattern in lanes 9 and 10. U-umc1268 showed a different band pattern in lanes 9 and10. Thus, the genetic purity of the maize seed lot was $96 \%$.

\section{Discussion}

\section{Adapter-primers design}

Novel adapter-primers were designed for UM-PCR in this study. The design of primers is very important for multiplex PCR, because the specificity and melting temperature of the primers are more critical than for routine PCR [26]. Primers with similar annealing temperatures are usually chosen for conventional multiplex PCR. However, for UM-PCR, it is not necessary to consider the differences in annealing temperatures of SSR primers. In this study, two 18 bp adapters are added to the 5' end of the forward and the reverse SSR primers. The adapters improve the specificity and melting temperature of the SSR primers, and the differences in melting temperatures among the adapter-primers is smaller than for SSR primers. Nevertheless, not all adapters are suitable for UM-PCR, e.g., the common adapter (5'-CCTTCCTTCCTTCCCCCC-3') is not optimal. This may be because the sequence of the common adapter occurs frequently in the maize genome. The design of adapter-primers needs to consider the sequence of adapters: It is better that the sequence of the adapters is rare. The annealing temperature of adapter-primers reaches about $70^{\circ} \mathrm{C}$. In addition, the formation of hairpin structures and cross dimers among the five pairs of primers should be minimized. There should be no more than six consecutive complementary base pairs. UM-PCR could detect more than 10 pairs of SSR primers simultaneously if the adapter-primers are fluorescently labeled. 


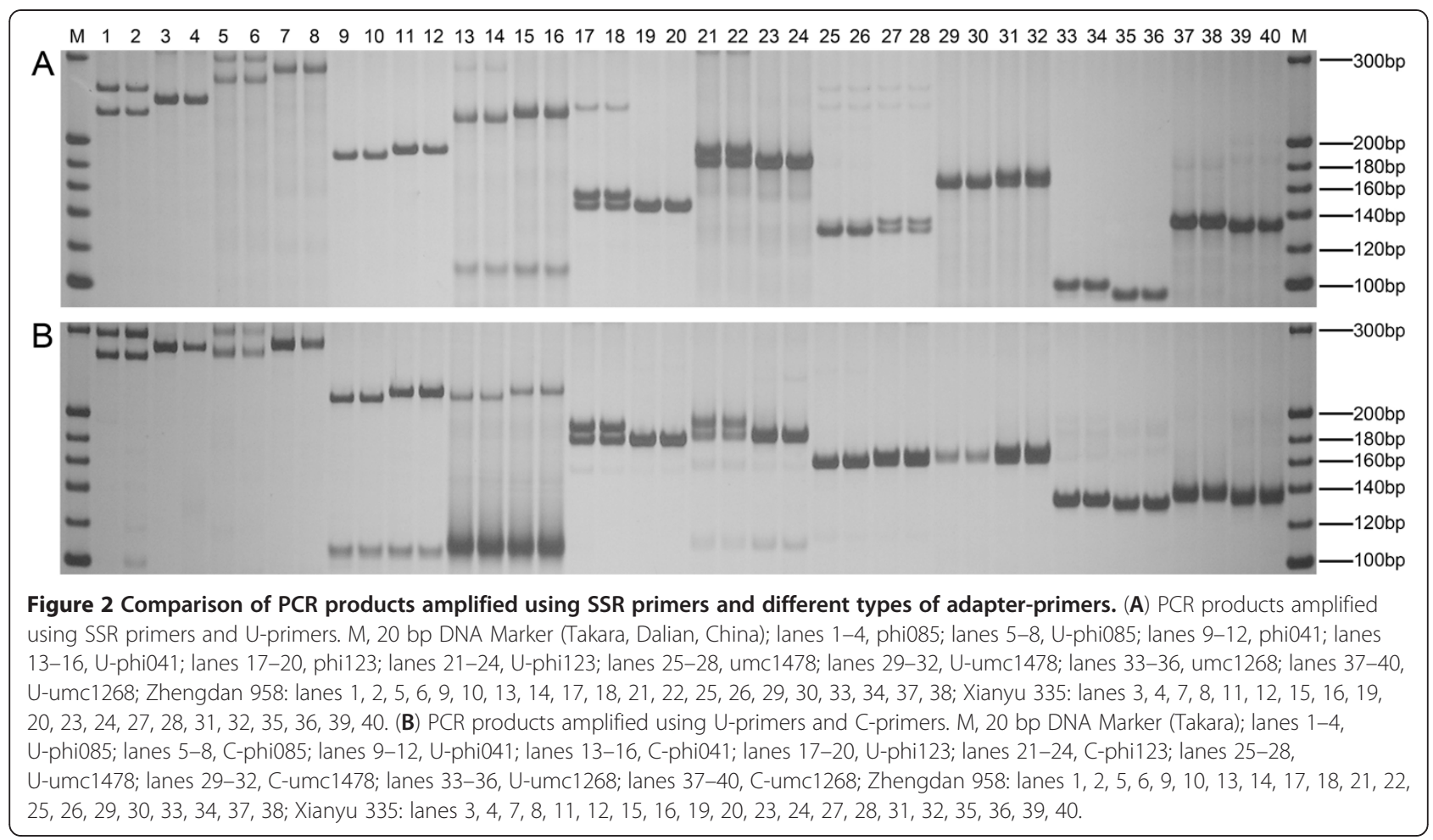

\section{The amplification procedure of UM-PCR design}

After optimization, UM-PCR amplification was performed in "Two Rounds Mode". The One by One Annealing Round (the first three cycles) is different from touchdown PCR. In the first two cycles of the first round, primers bind to the specific maize sequences in the templates, whereas universal adapters do not have any target templates. The templates for the universal adapters begin to be synthesized from the second cycle of the first round, and universal adapters and primers commence full amplification of the templates from the third cycle of the first round. The reason why touchdown PCR is not used in UM-PCR is that it would increase nonspecific amplification products. Disproportionate amplification cannot be avoided among different primers in conventional multiplex PCR, because the amplification efficiencies of primers may be different in the linear and exponential amplification phases [45]. However, UM-PCR partly solves the problem using the "Two Rounds Mode" and reduces non-specific amplification products.

\section{The superiority of UM-PCR}

First, UM-PCR can partly overcome the disadvantages of conventional multiplex PCR, such as low amplification efficiency and variable efficiency on different templates. Conventional multiplex PCR does not usually result in equal signals from multiple target fragments [26,44]. However, the adapter-primers are designed to amplify DNA templates at a similar efficiency using the "Two
Rounds Mode" and by adjusting the amount of adapterprimers. UM-PCR can also overcome the shortcomings of traditional maize seed genetic purity testing methods, such as long processing time; the traditional tests are affected by human factors, and are vulnerable to the impact of environmental conditions [8,9,13]. Using the UM-PCR method, five SSR loci can be identified once, and it is easier and more sensitive than conventional methods. Last, the universality of conventional multiplex PCR is poor, and some technical problems remain unsolved [41]. However, UM-PCR greatly improves the universality of multiplex PCR. The use of universal adapters and the "Two Rounds Mode" means that UMPCR is not only good for testing the genetic purity of maize seeds, but can also be widely applied in other areas (e.g., analyses of polymorphisms, quantitative assays and identifications of species). Further research to develop a rapid detection technique of the genetic purity of maize seeds that is combined with UM-PCR is ongoing.

\section{Conclusions}

The novel method, UM-PCR, which involves the design of adapter-primers and the establishment of the "Two Rounds Mode", can be used for the identification five SSR loci simultaneously, and could potentially be used to identify more than five SSR loci. Thus, it can be widely applied in multiplex PCR assays, especially in testing the genetic purity of seeds. 


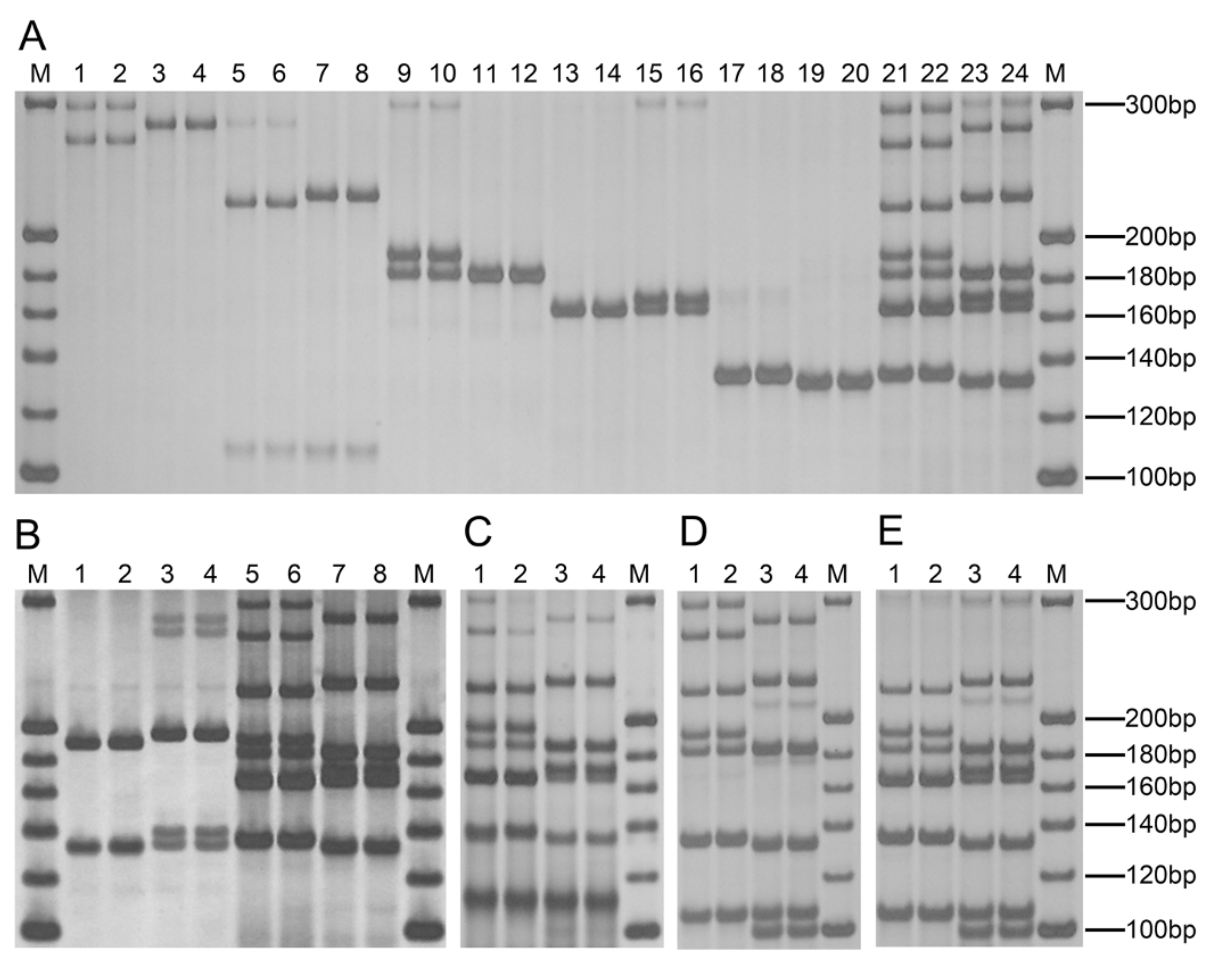

Figure 3 Comparison of UM-PCR products amplified using SSR primers and different types of adapter-primers. (A) Comparison of single PCR products and quintuple PCR products amplified using U-primers. M, 20 bp DNA Marker (Takara); lanes 1-4, U-phi085; lanes 5-8, U-phi041; from 9 to 12, U-phi123; lanes 13-16, U-umc1478; lanes 17-20, U-umc1268; lanes 21-24 contain five pairs of U-primers (U-phi085, U-phi041, Uphi123, U-umc1478 and U-umc1268). Zhengdan 958: lanes 1, 2, 5, 6, 9, 10, 13, 14, 17, 18, 21, 22; Xianyu 335: lanes 3, 4, 7, 8, 11, 12, 15, 16, 19, 20, 23, 24. (B) Comparison of quintuple PCR products amplified using SSR primers and U-primers. M, 20 bp DNA Marker (Takara); lanes 1-4 contain five pairs of SSR primers (phi085, phi041, phi123, umc1478 and umc1268); lanes 5-8 contain five pairs of U-primers (U-phi085, U-phi041, U-phi123, U-umc1478 and U-umc1268); Zhengdan 958: lanes 1, 2, 5, 6; Xianyu 335: lanes 3, 4, 7, 8. (C) Quintuple PCR products amplified using C-primers. Lanes 1-4 contain five pairs of C-primers (C-phi085, C-phi041, C-phi123, C-umc1478 and C-umc1268); M, 20 bp DNA Marker (Takara); Zhengdan 958: lanes 1, 2; Xianyu 335: lanes 3, 4. (D) Quintuple PCR products amplified using U-primers. Lanes 1-4 contain five pairs of U-primers (U-phi085, U-phi041, U-phi123, U-umc1268 and U-phi120); M, 20 bp DNA Marker (Takara); Zhengdan 958: lanes 1, 2; Xianyu 335: lanes 3, 4. (E) Quintuple PCR products amplified using U-primers. Lanes 1-4 contain five pairs of U-primers (U-phi041, U-phi123, U-umc1478, U-umc1268 and U-phi120); M, 20 bp DNA Marker (Takara); Zhengdan 958: lanes 1, 2; Xianyu 335: lanes 3, 4.

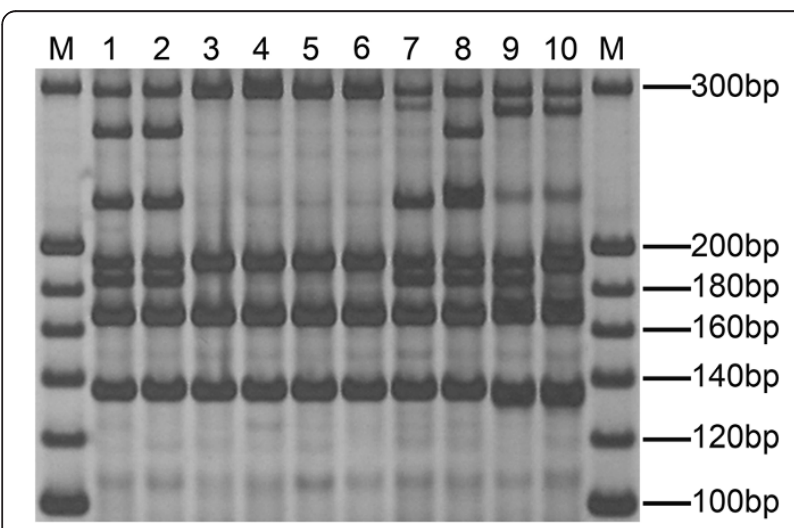

Figure $4 \mathrm{Gel}$ region showing the detection of genetic purity of a maize seed lot. $M, 20$ bp DNA Marker (Takara); lanes 1-10 contain five pairs of U-primers (U-phi085, U-phi041, U-phi123, U-umc1478 and U-umc1268); lanes 1-2, standard bands of Zhengdan 958 (for convenience, the standard bands of only two seeds are shown); lanes 3-6, female parent's bands of Zhengdan 958; lanes 7-10, the bands generated from off-type seeds.

\section{Methods}

\section{Materials}

Maize cultivars Zhengdan 958 and Xianyu 335 were used.

\section{DNA extraction}

DNA was extracted from the maize dry seeds (Zhengdan 958 and Xianyu 335) for seed genetic purity testing. A seed was crushed and then placed in a $1.5 \mathrm{~mL}$ centrifuge tube. We then preheated $500 \mu \mathrm{L}$ DNA extracting solution to $65^{\circ} \mathrm{C}(0.5 \mathrm{M} \mathrm{NaCl}, 100 \mathrm{mM}$ Tris- $\mathrm{HCl} \mathrm{pH} 8.0$, and $50 \mathrm{mM}$ EDTA, 5\% SDS, 1\% PVP) and added this. The solution was mixed and incubated at $65^{\circ} \mathrm{C}$ for $45 \mathrm{~min}$. The sample was then centrifuged at $10000 \mathrm{~g}$ for $10 \mathrm{~min}$ at room temperature. The supernatant was transferred to a fresh centrifuge tube. An equal volume of phenol/chloroform/isoamyl alcohol (25:24:1 v/v/v) was added and mixed. The sample was centrifuged at $10000 \mathrm{~g}$ for $10 \mathrm{~min}$ at room temperature, and the supernatant was transferred to a fresh centrifuge tube. An 
equal volume of chloroform/isoamyl alcohol (24:1 v/v) was added and mixed. The sample was centrifuged again and the supernatant removed to a fresh tube. An equal volume of isopropanol was added and stood at room temperature for $3 \mathrm{~min}$. The sample was centrifuged at $10000 \mathrm{~g}$ for $5 \mathrm{~min}$ and the supernatant was discarded. The pellet was washed twice with 150 $\mu \mathrm{L} 70 \%$ ethanol and air dried before being resuspended in $50 \mu \mathrm{L} 1 \times \mathrm{TE}(10 \mathrm{mM}$ Tris- $\mathrm{HCl} \mathrm{pH} 8.0$, $0.1 \mathrm{mM}$ EDTA) buffer. The DNA solution was used directly as the template for PCR amplification or stored at $-20^{\circ} \mathrm{C}$.

Table 1 Sequences of adapters and primers

\begin{tabular}{|c|c|c|c|}
\hline Name & Sequence $\left(5^{\prime}\right.$ to $\left.3^{\prime}\right)$ & $\operatorname{Tm}\left({ }^{\circ} \mathrm{C}\right)$ & References \\
\hline universal adapter-F & CTCGTAGACTGCGTACCA & 57.30 & This study \\
\hline universal adapter-R & TACTCAGGACTCATCGTC & 55.02 & This study \\
\hline common adapter & сСТтССтTССТTСССССC & 61.86 & Bai et al., 2009 \\
\hline phi085-F & AGCAGAACGGCAAGGGCTACT & 61.92 & MaizeGDB \\
\hline phi085-R & TTTGGCACACCACGACGA & 57.30 & MaizeGDB \\
\hline U-phi085-F & CTCGTAGACTGCGTACCAAGCAGAACGGCAAGGGCTACT & 72.61 & This study \\
\hline U-phi085-R & TACTCAGGACTCATCGTCTITGGCACACCACGACGA & 70.05 & This study \\
\hline C-phi085-F & сСтTCCTTCCTTCCCCCCAGCAGAACGGCAAGGGCTACT & 74.71 & This study \\
\hline C-phi085-R & сCTTCCTTCCTTCCCCCCTITGGCACACCACGACGA & 73.47 & This study \\
\hline phi041-F & TTGGCTCCCAGCGCCGCAAA & 63.95 & MaizeGDB \\
\hline phi041-R & GATCCAGAGCGATTTGACGGCA & 61.94 & MaizeGDB \\
\hline U-phi041-F & CTCGTAGACTGCGTACCATTGGCTCCCAGCGCCGCAAA & 73.96 & This study \\
\hline U-phi041-R & TACTCAGGACTCATCGTCGATCCAGAGCGATTTGACGGCA & 71.33 & This study \\
\hline C-phi041-F & сСтTCCTTCCTTCCCCCCTTGGCTCCCAGCGCCGCAAA & 76.12 & This study \\
\hline C-phi041-R & сCTTCCTTCCTTCCCCCCGATCCAGAGCGATTTGACGGCA & 74.40 & This study \\
\hline phi123-F & GGAGACGAGGTGCTACTTCTTCAA & 61.97 & MaizeGDB \\
\hline phi123-R & TGTGGCTGAGGCTAGGAATCTC & 61.94 & MaizeGDB \\
\hline U-phi123-F & CTCGTAGACTGCGTACCAGGAGACGAGGTGCTACTTCTTCAA & 71.87 & This study \\
\hline U-phi123-R & TACTCAGGACTCATCGTCTGTGGCTGAGGCTAGGAATCTC & 71.33 & This study \\
\hline C-phi123-F & СCTTCCTTCCTTCCCCCCGGAGACGAGGTGCTACTTCTTCAA & 73.82 & This study \\
\hline C-phi123-R & сСтTCCTTCCTTCCCCCCTGTGGCTGAGGCTAGGAATCTC & 74.40 & This study \\
\hline umc1478-F & GAAGCTTCTCCTCTCGCGTCTC & 63.80 & MaizeGDB \\
\hline umc1478-R & CAGTCCCAGACCCTAGCTCAGTC & 65.52 & MaizeGDB \\
\hline U-umc1478-F & CTCGTAGACTGCGTACCAGAAGCTTCTCCTCTCGCGTCTC & 73.38 & This study \\
\hline U-umc1478-R & TACTCAGGACTCATCGTCCAGTCCCAGACCCTAGCTCAGTC & 73.10 & This study \\
\hline C-umc1478-F & сCTTCCTTCCTTCCCCCCGAAGCTTCTCCTCTCGCGTCTC & 75.43 & This study \\
\hline C-umc1478-R & сCTTCCTTCCTTCCCCCCCAGTCCCAGACCCTAGCTCAGTC & 76.10 & This study \\
\hline umc1268-F & ACGAACAACCTAGCACAGTCCTAAA & 60.34 & MaizeGDB \\
\hline umc1268-R & CAAGGCGGTTACCAAGTTACATC & 60.26 & MaizeGDB \\
\hline U-umc1268-F & CTCGTAGACTGCGTACCAACGAACAACCTAGCACAGTCCTAAA & 70.70 & This study \\
\hline U-umc1268-R & TACTCAGGACTCATCGTCCAAGGCGGTTACCAAGTTTACATC & 69.92 & This study \\
\hline C-umc1268-F & сСтTCCTTCCTTCCCCCCACGAACAACCTAGCACAGTCCTAAA & 71.93 & This study \\
\hline C-umc1268-R & сCTTCCTTCCTTCCCCCCCAAGGCGGTTACCAAGTTTACATC & 72.85 & This study \\
\hline phi120-F & TGATGTCCCAGCTCTGAACTGAC & 61.92 & MaizeGDB \\
\hline phi120-R & GACTCTCACGGCGAGGTATGA & 61.95 & MaizeGDB \\
\hline U-phi120-F & CTCGTAGACTGCGTACCATGATGTCCCAGCTCTGAACTGAC & 72.10 & This study \\
\hline U-phi120-R & TACTCAGGACTCATCGTCGACTCTCACGGCGAGGTATGA & 71.56 & This study \\
\hline
\end{tabular}

Tms are taken from the primer synthesis report card. 


\section{Adapter-primers design}

In this study, universal adapters were designed. Universal adapter-F (5'-CTCGTAGACTGCGTACCA-3') and universal adapter-R (5'-TACTCAGGACTCATCGTC-3') designed based on the EcoRI-adapter and the MseIadapter of AFLP, respectively [48]; however, their sequences are not identical to the AFLP adapters. Both universal adapters were single stranded. Universal adapter-F and universal adapter- $\mathrm{R}$ were linked to the $5^{\prime}$ end of the forward and reverse SSR primers, respectively (U-primers include universal adapters and SSR primers). In this way, the difference of annealing temperature among the primers could be reduced, and the annealing temperature of adapter-primers would reach about $70^{\circ} \mathrm{C}$. The designed primers were checked for their propensity to form hairpin structures and cross dimers, which should be minimized. To verify the universality of UM-PCR, we selected some highly specific SSR primers whose annealing temperatures were different. Among these primers, the lowest annealing temperature was about $10^{\circ} \mathrm{C}$ lower than the highest annealing temperature. To verify the feasibility of the adapters, we also tested a common adapter (5'-CCTTCCTTCCTTCCCCCC-3') that was taken from reference [26]. The adapters and primers are shown in Table 1.

\section{PCR procedure}

To verify the reliability of UM-PCR, a series of PCR assays were carried out. All the UM-PCR reactions were conducted using a Biometra PCR system (Biometra, Gottingen, Germany) in a $20 \mu \mathrm{L}$ reaction volume, which contained $10 \mu \mathrm{L} 2 \times$ Power Taq PCR MasterMix (BioTeke,

Table 2 The UM-PCR procedure ("Two Rounds Mode")

$\times 3 \begin{cases}\hline \text { Temperature }\left({ }^{\circ} \mathbf{C}\right) & \text { Time } \\ \hline 94 & 5 \mathrm{~min} \\ 94 & 40 \mathrm{~s} \\ \text { annealing temperature of primer } 1 & 20 \mathrm{~s} \\ \text { annealing temperature of primer } 2 & 20 \mathrm{~s} \\ \text { annealing temperature of primer 3 } & 20 \mathrm{~s} \\ \text { annealing temperature of primer } 4 & 20 \mathrm{~s} \\ \text { annealing temperature of primer } 5 & 20 \mathrm{~s} \\ 72 & 30 \mathrm{~s} \\ & \\ 94 & 40 \mathrm{~s} \\ 70 & 50 \mathrm{~s} \\ 72 & 10 \mathrm{~min}\end{cases}$

In the first round (the first three cycles), annealing temperatures that are optimized in accordance with the Tm of normal SSR primers are sorted in descending order. Annealing temperatures may be different in various combinations of U-primers.
Beijing, China), $3 \mu \mathrm{L}$ DEPC $\mathrm{H}_{2} \mathrm{O}, 0.5 \mu \mathrm{L}$ of $10 \mu \mathrm{M}$ (a total of five pairs of adapter-primers) adapter-primers (Sangon, Shanghai, China) and $2 \mu \mathrm{L}$ DNA. UM-PCR amplification was implemented using a novel PCR procedure, termed the "Two Rounds Mode" (3 and 28-32 cycles). The first round (the first three cycles) was termed the "One by One Annealing Round". The second round (28-32 cycles, usually 30 cycles) combines annealing with extension. The final thermal cycling program is shown in Table 2, and the basic principle of the adapter-primers and UM-PCR method is outlined in Figure 1. The routine PCR reactions were also conducted using a Biometra PCR system (Biometra) in a $20 \mu \mathrm{L}$ reaction volume, which contained $10 \mu \mathrm{L}$ $2 \times$ Power Taq PCR MasterMix (BioTeke), $7 \mu \mathrm{L}$ DEPC $\mathrm{H}_{2} \mathrm{O}, 0.5 \mu \mathrm{L}$ of $10 \mu \mathrm{M}$ primers (Sangon) and $2 \mu \mathrm{L}$ DNA. The final thermal cycling included an initial 5 min denaturation at $94^{\circ} \mathrm{C} ; 30$ cycles for $40 \mathrm{~s}$ at $94^{\circ} \mathrm{C}, 30 \mathrm{~s}$ at the annealing temperature of the primer, and $30 \mathrm{~s}$ at $72^{\circ} \mathrm{C}$; and a final extension for $10 \mathrm{~min}$ at $72^{\circ} \mathrm{C}$.

\section{Gel electrophoresis}

PCR products were electrophoresed in 9\% polyacrylamide gel for $3 \mathrm{~h}(10 \mathrm{~V} / \mathrm{cm})$ in a Tris-Boric acid-EDTA buffer [0.08 M Tri-HCl (pH 8.5), 0.08 M Boric acid and $2.4 \mathrm{mM}$ EDTA]. After electrophoresis, the gel was stained by $0.2 \%$ silver and developed by $3 \% \mathrm{NaOH}$ and $5 \mathrm{~mL} \mathrm{37 \%} \mathrm{formaldehyde} \mathrm{per} \mathrm{liter.} \mathrm{The} \mathrm{gel} \mathrm{was} \mathrm{then}$ photographed with a camera.

\section{Additional file}

Additional file 1: Detection of genetic purity of a maize seed lot (200 seeds, Zhengdan 958). The bands generated from the female parent of Zhengdan 958 are in red boxes, and the bands generated from the off-type seeds are in yellow boxes.

\section{Abbreviations}

UM-PCR: Universal Multiplex PCR; U-primers: Universal adapter primers contain universal adapter sequences and specific primer sequences; Cprimers: Common adapter primers contain common adapter sequences and specific primer sequences.

\section{Competing interests}

Both authors declare that they have no competing interests.

\section{Authors' contributions}

DW developed the technique and drafted the manuscript. CZ supervised the project and revised the manuscript. All authors read and approved the final manuscript.

\footnotetext{
Acknowledgements

We thank the Special Fund of Agricultural Significant Application Technique Innovation of Shandong Province; the Special Fund of Crop Seed Industrial Engineering of Shandong Province; the Innovative Team Fund of Modern Agricultural Industrial Technique System of Shandong Province; and the National Transgenic Animals and Plants Research Project (grant 2011ZX08011-006).
}

Received: 13 July 2012 Accepted: 25 July 2012

Published: 15 August 2012 


\section{References}

1. Choudhary R, Paliwal J, Jayas DS: Classification of cereal grains using wavelet, morphological, colour, and textural features of non-touching kernel images. Biosyst Eng 2008, 99(3):330-337.

2. Hoffman D, Hang A, Larson S, Jones B: Conversion of an RAPD marker to an STS marker for barley variety identification. Plant Mol Biol Rep 2003, 21(1):81-91.

3. Hulya I: RAPD markers assisted varietal identification and genetic purity test in pepper, Capsicum annuum. Sci Hortic-Amsterdam 2003, 97(3):211-218.

4. Liu L, Wang Y, Gong Y, Zhao T, Liu G, Li X, Yu F: Assessment of genetic purity of tomato (Lycopersicon esculentum L.) hybrid using molecular markers. Sci Hortic-Amsterdam 2007, 115(1):7-12.

5. Liu L, Liu G, Gong Y, Dai W, Wang Y, Yu F, Ren Y: Evaluation of Genetic Purity of $F_{1}$ Hybrid Seeds in Cabbage with RAPD, ISSR, SRAP, and SSR Markers. Hortscience 2007, 42(3):724-727.

6. Macko A, Grzebelus D: DcMaster transposon display markers as a tool for diversity evaluation of carrot breeding materials and for hybrid seed purity testing. J Appl Genet 2008, 49(1):33-39.

7. Massaux C, Sindic M, Lenartz J, Sinnaeve G, Bodson B, Falisse A, Dardenne P, Deroanne $C$ : Variations in physicochemical and functional properties of starches extracted from European soft wheat (Triticum aestivum L.): The importance to preserve the varietal identity. Carbohyd Polym 2008, 71(1):32-41.

8. Naresh V, Yamini K, Rajendrakumar P, Dinesh Kumar V: EST-SSR markerbased assay for the genetic purity assessment of safflower hybrids. Euphytica 2009, 170(3):347-353.

9. Pattemore JA, Rice N, Marshall DF, Waugh R, Henry RJ: Cereal variety identification using MALDI-TOF mass spectrometry SNP genotyping. J Cereal Sci 2010, 52(3):356-361

10. Pranavi B, Sitaram G, Yamini KN, Kumar VD: Development of EST-SSR markers in castor bean (Ricinus communis L.) and their utilization for genetic purity testing of hybrids. Genome 2011, 54:684-691.

11. Sundaram R, Naveenkumar B, Biradar S, Balachandran S, Mishra B, llyasAhmed M, Viraktamath B, Ramesha M, Sarma N: Identification of informative SSR markers capable of distinguishing hybrid rice parental lines and their utilization in seed purity assessment. Euphytica 2008, 163(2):215-224

12. Terzi V, Morcia C, Gorrini A, Stanca AM, Shewry PR, Faccioli P: DNA-based methods for identification and quantification of small grain cereal mixtures and fingerprinting of varieties. J Cereal Sci 2005, 41(3):213-220.

13. Wiwart M, Suchowilska E, Lajszner W, Graban $Ł$ : Identification of hybrids of spelt and wheat and their parental forms using shape and color descriptors. Comput Electron Agr 2012, 83:68-76.

14. Wu M, Jia X, Tian L, Lv B: Rapid and Reliable Purity Identification of F1 Hybrids of Maize (Zea may L.) Using SSR Markers. Mol, Plant Breeding 2006, 3(4):381-384

15. Zhou X, Shen S, Wu D, Sun J, Shu Q: Introduction of a xantha mutation for testing and increasing varietal purity in hybrid rice. Field Crop Res 2006, 96(1):71-79.

16. Bacchetta G, García PE, Grillo O, Mascia F, Venora G: Seed image analysis provides evidence of taxonomical differentiation within the Lavatera triloba aggregate (Malvaceae). Flora 2011, 206(5):468-472.

17. Chen $X, X u n Y, L i W$, Zhang J: Combining discriminant analysis and neural networks for corn variety identification. Comput Electron Agr 2010, 71(Supplement 1(0)):S48-S53.

18. Dubey BP, Bhagwat SG, Shouche SP, Sainis JK: Potential of Artificial Neural Networks in Varietal Identification using Morphometry of Wheat Grains. Biosyst Eng 2006, 95(1):61-67.

19. Granitto PM, Verdes PF, Ceccatto HA: Large-scale investigation of weed seed identification by machine vision. Comput Electron Agr 2005, 47(1):15-24.

20. Manickavasagan A, Sathya G, Jayas DS: Comparison of illuminations to identify wheat classes using monochrome images. Comput Electron Agr 2008, 63(2):237-244.

21. Medina W, Skurtys O, Aguilera JM: Study on image analysis application for identification Quinoa seeds (Chenopodium quinoa Willd) geographical provenance. LWT- Food Sci Technol 2010, 43(2):238-246.

22. Yan $X$, Liu S, Zhang C, Wang J: Purity identification of maize seed based on color characteristics. Transactions CSAE 2010, 26:46-50.

23. Granitto PM, Navone HD, Verdes PF, Ceccatto HA: Weed seeds identification by machine vision. Comput Electron Agr 2002, 33(2):91-103.

24. Smith JSC, Chin ECL, Shu H, Smith OS, Wall SJ, Senior ML, Mitchell SE, Kresovich S, Ziegle J: An evaluation of the utility of SSR loci as molecular markers in maize (Zea mays L.): comparisons with data from RFLPS and pedigree. Theor Appl Genet 1997, 95(1):163-173.

25. Armani A, Castigliego L, Tinacci L, Gianfaldoni D, Guidi A: Multiplex conventional and real-time PCR for fish species identification of Bianchetto (juvenile form of Sardina pilchardus), Rossetto (Aphia minuta), and Icefish in fresh, marinated and cooked products. Food Chem 2012, 133(1):184-192.

26. Bai W, Xu W, Huang K, Yuan Y, Cao S, Luo Y: A novel common primer multiplex PCR (CP-M-PCR) method for the simultaneous detection of meat species. Food Control 2009, 20(4):366-370.

27. Chang Y, Yeh K, Hsu NC, Lin S, Chang T, Chang J: Detection of $\mathrm{N}-, \mathrm{H}$-, and KRAS codons 12, 13, and 61 mutations with universal RAS primer multiplex PCR and $\mathrm{N}-, \mathrm{H}$-, and $\mathrm{KRAS}$-specific primer extension. $\mathrm{Clin}$ Biochem 2010, 43(3):296-301.

28. Espiñeira M, Atanassova M, Vieites JM, Santaclara FJ: Validation of a method for the detection of five species, serogroups, biotypes and virulence factors of Vibrio by multiplex PCR in fish and seafood. Food Microbiol 2010, 27(1):122-131.

29. Gunson R, Maclean A, Davies E, Bennett S, Miller R, Carman WF: Development of a multiplex real-time RT-PCR that allows universal detection of influenza A viruses and simultaneous typing of influenza A/ H1N1/2009 virus. J Virol Methods 2010, 163(2):258-261.

30. Hu Q, Tu J, Han X, Zhu Y, Ding C, Yu S: Development of multiplex PCR assay for rapid detection of Riemerella anatipestifer, Escherichia coli, and Salmonella enterica simultaneously from ducks. J Microbiol Meth 2011, 87(1):64-69

31. Ao J, Li Q, Gao X, Yu Y, Li L, Zhang M: A multiplex nested PCR assay for the simultaneous detection of genetically modified soybean, maize and rice in highly processed products. Food Control 2011, 22(10):1617-1623.

32. Khamrin P, Okame M, Thongprachum A, Nantachit N, Nishimura S, Okitsu S, Maneekarn N, Ushijima H: A single-tube multiplex PCR for rapid detection in feces of 10 viruses causing diarrhea. J Virol Methods 2011, 173(2):390-393.

33. Kim H, Lee H, Lee K, Cho J: Simultaneous detection of Pathogenic Vibrio species using multiplex real-time PCR. Food Control 2012, 23(2):491-498

34. Kuwayama M, Shigemoto N, Oohara S, Tanizawa Y, Yamada H, Takeda Y, Matsuo T, Fukuda S: Simultaneous detection of virulence factors from a colony in diarrheagenic Escherichia coli by a multiplex PCR assay with Alexa Fluor-labeled primers. J Microbiol Meth 2011, 86(1):119-120.

35. Langrell SRH, Morel O, Robin C: Touchdown nested multiplex PCR detection of Phytophthora cinnamomi and P. cambivora from French and English chestnut grove soils. Fungal Biol 2011, 115(7):672-682.

36. Lu I, Lin C, Pan T: Establishment of a system based on universal multiplex-PCR for screening genetically modified crops. Anal Bioanal Chem 2010, 396(6):2055-2064.

37. Milheirico C, Oliveira DC, de Lencastre H: Multiplex PCR strategy for subtyping the staphylococcal cassette chromosome mec type IV in methicillin-resistant Staphylococcus aureus: 'SCCmec IV multiplex'. $J$ Antimicrob Chemother 2007, 60(3):42-48.

38. Pichon J, Bonnaud B, Cleuziat P, Mallet F: Multiplex degenerate PCR coupled with an oligo sorbent array for human endogenous retrovirus expression profiling. Nucleic Acids Res 2006, 34(6)::46.

39. Rugman-Jones $\mathrm{P}$, Forster $\mathrm{L}$, Guerrieri E, Luck R, Morse J, Monti M, Stouthamer R: Taxon-specific multiplex-PCR for quick, easy, and accurate identification of encyrtid and aphelinid parasitoid species attacking soft scale insects in California citrus groves. Biocontrol 2011, 56(3):265-275.

40. Sankuntaw N, Sukprasert S, Engchanil C, Kaewkes W, Chantratita W, Pairoj V, Lulitanond V: Single tube multiplex real-time PCR for the rapid detection of herpesvirus infections of the central nervous system. Mol Cell Probe 2011, 25(2-3):114-120.

41. Shigemori Y, Mikawa T, Shibata T, Oishi M: Multiplex PCR: use of heatstable Thermus thermophilus RecA protein to minimize non-specific PCR products. Nucleic Acids Res 2005, 33(14):e126.

42. Wang C, Jong Y, Chang J, Chen Y, Wu S: Universal fluorescent multiplex PCR and capillary electrophoresis for evaluation of gene conversion between SMN1 and SMN2 in spinal muscular atrophy. Anal Bioanal Chem 2010, 397(6):2375-2383.

43. Wang R, Huang J, Zhang W, Lin G, Lian J, Jiang L, Lin H, Wang S, Wang S: Detection and identification of Vibrio parahaemolyticus by multiplex PCR and DNA-DNA hybridization on a microarray. J Genet Genomics 2011, 38(3):129-135. 
44. Xu W, Bai W, Luo Y, Yuan Y, Zhang W, Guo X, Huang K: A novel common single primer multiplex polymerase chain reaction (CSP-M-PCR) method for the identification of animal species in minced meat. J Sci Food Agr 2008, 88(15):2631-2637.

45. Yuan Y, Xu W, Zhai Z, Shi H, Luo Y, Chen Z, Huang K: Universal primermultiplex PCR approach for simultaneous detection of Escherichia coli, Listeria monocytogenes, and Salmonella spp. in food samples. J Food Sci 2009, 74(8):M446-M452.

46. Dehainault C, Lauge A, Caux-Moncoutier V, Pages-Berhouet S, Doz F, Desjardins L, Couturier J, Gauthier-Villars M, Stoppa-Lyonnet D, Houdayer C: Multiplex PCR/liquid chromatography assay for detection of gene rearrangements: application to RB1 gene. Nucleic Acids Res 2004, 32(18):e139.

47. Chamberlain J, Gibbs R, Ranier J, Nguyen P, Caskey C: Deletion screening of the Duchenne muscular dystrophy locus via multiplex DNA amplification. Nucleic Acids Res 1988, 16(23):11141-11156.

48. Vos $\mathrm{P}$, Hogers R, Bleeker M, Reijans M, van de Lee T, Hornes M, Frijters A, Pot J, Peleman J, Kuiper M, Zabeau M: AFLP: a new technique for DNA fingerprinting. Nucleic Acids Res 1995, 23(21):4407-4414.

doi:10.1186/1746-4811-8-32

Cite this article as: Wen and Zhang: Universal Multiplex PCR: a novel method of simultaneous amplification of multiple DNA fragments. Plant Methods 2012 8:32

\section{Submit your next manuscript to BioMed Central and take full advantage of:}

- Convenient online submission

- Thorough peer review

- No space constraints or color figure charges

- Immediate publication on acceptance

- Inclusion in PubMed, CAS, Scopus and Google Scholar

- Research which is freely available for redistribution 